\title{
A EDUCAÇÃO AMBIENTAL COMO DISCIPLINA
}

Sergio Mattos Fonseca ${ }^{1}$

Resumo: Através do documento final da Conferência de Tbilisi na Geórgia (1977), percebe-se a dimensão atribuída à Educação em relação ao meio ambiente, não somente restringindo ao meio físico, mas entendendo as interrelações com o meio social e cultural, relacionando essa com o modelo de desenvolvimento humano. A transversalidade da questão ecológica é trabalhada nas ONGs através dos seus diversos projetos desenvolvidos. Um exemplo pioneiro na Educação é a experiência da APREC Ecossistemas Costeiros, uma organização ambientalista com sede no Rio de Janeiro. Através do Centro de Ensino Interdisciplinar - CEI onde a Educação Ambiental é internalizada como disciplina e alcança os alunos que frequentam os cursos do ensino básico. Os alunos podem ter nota 10 nas provas, mas ainda assim, jogar lixo na rua, pescar peixes - fêmeas prontas para reproduzir, atear fogo no mato indiscriminadamente, ou realizar outro tipo de ação danosa, seja por não perceberem a extensão dessas ações ou por não se sentirem responsáveis pelo mundo em que vivem. A formulação do projeto educacional do Centro de Ensino Interdisciplinar - CEI - internalizando a Educação Ambiental como disciplina por meio da discussão, decisão e encaminhamentos conjuntos, com atribuição de responsabilidades pelos corpos docentes e discentes, possibilita superar o fracionamento do saber. As divergências de interesses, vários exercícios profissionais e as diferentes escalas de valores, por terem que se articular na efetivação do projeto pedagógico, contribui para a construção de uma cidadania com consciência ecológica.

Palavras-chave: Educação; Educação Ambiental; Meio Ambiente; Cidadania.

${ }^{1}$ Fundação de Amparo a Escola Técnica do Estado do Rio de Janeiro. E-mail: sergio@aprec.org.br

Revbea, São Paulo, V. 11, № 1: 305-314, 2016.

revista brasileira

educação ambiental 


\section{Introdução}

\section{Saberes e Atividade Docente}

A superação do fracasso e das desigualdades escolares, este o desafio que se coloca aos professores, cuja função de mediação nos processos constitutivos da cidadania dos alunos é cada vez mais importante, tanto quanto a formação desse professor para a missão. No que diz respeito à formação de professores, diversos autores têm demonstrado que os cursos de formação ao desenvolverem um currículo formal com conteúdos e atividades de estágios distanciados da realidade das escolas, numa perspectiva burocrática e cartorial que não dá conta de captar as contradições presentes na prática social de educar, pouco tem contribuído para gestar uma nova identidade do profissional docente (PICONEZ,1991; PIMENTA, 1994; LEITE, 1995 apud PIMENTA, 1994). No que se refere à formação contínua, a prática mais frequente tem sido a de realizar cursos de suplência e/ ou atualização dos conteúdos de ensino. Esses programas têm se mostrado pouco eficientes para alterar a prática docente e, consequentemente, as situações de fracasso escolar, por não tomarem a prática docente e pedagógica escolar nos seus contextos. Ao não as colocar como o ponto de partida e o de chegada da formação, acaba por, tão somente, ilustrar individualmente o professor, não the possibilitando articular e traduzir os novos saberes em novas práticas (FUSARI, 1988 apud PIMENTA, 1994).

A compreensão do trabalho docente demanda que este seja analisado enquanto categoria geral e em sua especificidade, a docência. Expressa a síntese de um saber pedagógico possuído pelo professor, e este é construído pelo professor no cotidiano de seu trabalho e que fundamenta sua ação docente, ou seja, é o saber que possibilita ao professor interagir com seus alunos, na sala de aula, no contexto da escola onde atua (AZZI, 1995). Conclui a autora que em sendo o trabalho do professor uma prática social, sua ação não deve, pois, limitar-se ao prático-utilitário. A superação do professor práticoutilitário encontra uma de suas condições em uma formação profissional que, tendo o trabalho docente como seu objeto de conhecimento, considere-o como uma prática, em sua relação de unidade com a teoria e considere, ainda, que "A prática determina o conhecimento, mas não é em si mesmo o conhecimento" (FREITAS, 1989 apud AZZI, 1995).

\section{Educação e Meio Ambiente}

Através do documento final da Conferência de Tbilisi na Geórgia (1977), percebe-se a dimensão atribuída à Educação em relação ao meio ambiente, não somente restringindo ao meio físico, mas entendendo as inter-relações com o meio social e cultural, relacionando essa com 0 modelo de desenvolvimento humano. A Conferência de Tbilisi reúne 41 recomendações em seu informe final, em um plano de ação mundial para a Educação Ambiental, ampliando o seu propósito fundamental de modo a mostrar as interdependências econômicas, políticas e ecológicas do mundo moderno.

Revbea, São Paulo, V. 11, № 1: 305-314, 2016. 
Define a Educação Ambiental como instrumento para preparar o indivíduo mediante a compreensão dos principais problemas do mundo contemporâneo, possibilitando-Ihe conhecimentos técnicos e as qualidades necessárias para desempenhar uma função produtiva com vistas a melhorar a vida e proteger o meio ambiente considerando os valores éticos. Sinaliza através da Recomendação 1-41 a importância do fomento à tomada de consciência das questões ambientais por parte de organismos como organizações profissionais de pessoal docente e organizações não governamentais, que se encarreguem diretamente da infância e da juventude, para que participem na formação e na execução de estratégias nacionais de Educação Ambiental (Tabela 1).

Tabela 1: Dimensão dos Principais Problemas Ambientais.

\begin{tabular}{|c|c|c|}
\hline GLOBAIS & NACIONAIS & MUNICIPAIS \\
\hline Emissão de GHG (Efeito & Tráfico de Animais Silvestres & Lixo Doméstico e \\
Estufa) & & Industrial \\
Ozônio & Chuva Ácida & Degradação de Mata Ciliar \\
\hline Acidentes e Lixo Nuclear & Poluição por Óleo em Mar & Poluição de Rios, Lagoas e \\
& Territorial & Baías \\
\hline
\end{tabular}

Sublinhada no décimo nono Período Especial das Sessões da Assembleia Geral (23 a 27 de junho de 1997), cinco anos após a Conferência do Rio, a Agenda 21 é certamente um dos documentos mais importantes gestado durante a Conferência das Nações Unidas Sobre o Meio Ambiente, a Rio 92 (IBAMA, 2000). Entretanto, apesar da sua dimensão, o texto da Agenda 21 continua sendo pouco conhecido, e somente neste início de século, dez anos após sua edição, observa-se uma preocupação maior para elaboração das Agendas 21 nacionais e locais. Em seu Capítulo 36.1 a Agenda 21 afirma que a Declaração e as recomendações da Conferência Intergovernamental de Tbilisi sobre Educação Ambiental, organizada pela UNESCO e PNUMA em 1977, ofereceram os princípios fundamentais para as propostas daquele documento.

No plano nacional, a primeira Conferência Nacional de Educação Ambiental foi realizada em Brasília no ano de 1997, levantando problemáticas e recomendações sistematizadas na Declaração de Brasília. Entre as recomendações destacam-se 5 temas: a Educação Ambiental e as Vertentes do Desenvolvimento Sustentável; Educação Ambiental Formal - Papel e Desafios; Educação Ambiental no Processo de Gestão Ambiental; A Educação 
Ambiental e as Políticas Públicas; Educação Ambiental, Ética e Formação da Cidadania - Educação, Comunicação e Informação da Sociedade. A política nacional de Educação Ambiental foi instituída pela lei 9.795 de 27 de abril de 1999, e com a criação da Diretoria de Educação Ambiental do Ministério do Meio Ambiente tem início a elaboração do Programa Nacional de Educação Ambiental, cujos princípios orientadores são: enfoque humanista, holístico, democrático e participativo; descentralização; integração e estabelecimento de parcerias, local, nacional e internacional; respeito à pluralidade e diversidade cultural do país; multi, inter e transdisciplinaridade; enfoque sistêmico; construção social de novos valores éticos. Em junho de 1999 o Ministério da Educação inicia a estruturação da Coordenação Geral de Educação Ambiental - COEA, trazendo a grande novidade ao ensino formal, através do atendimento à recomendação da pesquisa educacional da UNESCO e de tratados internacionais sobre EA, integrando esta às demais disciplinas. A COEA sinaliza alguns objetivos, os quais acreditamos que sejam importantes para 0 estabelecimento de uma via transversal entre a Educação e o Meio Ambiente:

- Incentivo a prática da EA nas escolas;

- Fortalecimento dos sistemas educacionais (secretarias), para incorporação da EA como prática na formação continuada;

- Difundir informações sobre EA no ensino formal;

- Implementar a política de EA de forma participativa e inclusiva.

\section{Metodologia}

\section{A Proposta Pedagógica CEI}

A transversalidade da questão ecológica é trabalhada nas ONGs através dos seus diversos projetos desenvolvidos. Um exemplo pioneiro na Educação é a experiência da APREC Ecossistemas Costeiros, uma organização ambientalista com sede no Rio de Janeiro. Através do Centro de Ensino Interdisciplinar - CEI onde a Educação Ambiental é internalizada como disciplina e alcança os alunos que frequentam os cursos do ensino básico.

A interdisciplinaridade, como questão epistemológica, surgiu no final do século passado, pela necessidade de dar uma resposta à fragmentação causada por uma epistemologia de cunho positivista. As ciências haviam-se dividido em muitas disciplinas e a interdisciplinaridade restabelecia, pelo menos, um diálogo entre elas, embora não resgatasse ainda a unidade e a totalidade do saber. Desde então, o conceito de interdisciplinaridade vem se desenvolvendo também nas ciências da educação, visando garantir a construção de um conhecimento globalizante, rompendo com as fronteiras das disciplinas. Para isso, integrar conteúdos não seria suficiente, é preciso uma atitude e postura interdisciplinar, atitude de busca, envolvimento, compromisso, reciprocidade diante do conhecimento. 
A ação pedagógica através da interdisciplinaridade aponta para a construção de uma escola participativa e decisiva na formação do sujeito social. O seu objetivo tornou-se a experimentação da vivência de uma realidade global, que se insere nas experiências cotidianas do aluno, do professor e da comunidade, e que na teoria positivista era compartimentalizada e fragmentada. Articular saber, conhecimento, vivência, escola, comunidade e meio ambiente tornou-se, nos últimos anos, o objetivo da interdisciplinaridade, que se traduz, na prática, em um trabalho coletivo e solidário na organização dessa nova escola. Um projeto interdisciplinar de educação marcado por uma visão geral da educação, num sentido progressista e libertador.

O Centro de Ensino Interdisciplinar da APREC integra conteúdos com a finalidade de discutir o mundo do trabalho e a construção da cidadania. Os princípios que fundamentam a proposta são:

- Educação para o trabalho: o trabalho é a principal fonte de sobrevivência dos indivíduos. A proposta de ensino destina-se aos jovens e adultos que tiveram que se inserir no mercado de trabalho sem estarem devidamente preparados. Para eles, busca-se promover uma educação básica, relacionada a questões cotidianas da vida produtiva, com o objetivo de contribuir para a melhoria da qualidade de vida dos cidadãos.

- Ensino contextualizado: o distanciamento entre os conteúdos do ensino e o universo sócio-cultural dos alunos tem sido frequentemente apontado como um dos responsáveis pelo fracasso escolar. Contextualizar o ensino significa trazer situações do cotidiano para a sala de aula, buscando relacionar teoria e prática, mostrando alternativas na forma de pensar, estimulando o raciocínio crítico.

- Aprendizado de habilidades básicas: desenvolver as capacidades de "aprender a aprender", pensar crítica e criativamente, tomar decisões e resolver problemas, transferindo e aplicando o conhecimento aprendido, observando:

- O uso eficiente dos recursos (tempo, dinheiro, materiais, espaço e pessoa): definir prioridades e valores; respeitar normas de qualidade e produtividade; organizar objetivos, atividades e ações no tempo e espaço.

- O uso de informações: identificar fontes de informação; avaliar a adequação das informações; distinguir fato de opinião; interpretar uma informação; comunicar-se adequadamente.

- Regras básicas de funcionamento de sistemas: sistemas sociais e organizacionais; relações entre os indivíduos e sistemas; direitos e deveres dos cidadãos e dos trabalhadores; meio ambiente organizacional, social e ecológico; questões de saúde; aplicação do conhecimento científico e tecnológico para identificar e resolver problemas concretos. 
O CEI combina o uso de multimeios com procedimentos dinâmicos. A metodologia do CEI se baseia nos seguintes conceitos:

- o cidadão é sujeito de sua aprendizagem;

- a experiência de vida e o que cada um já sabe é o ponto de partida do processo de aprendizagem;

- as novas informações, conceitos e experiências colocados ao alcance da cidadania promovem mudanças no conhecimento existente, contribuindo, a cada passo, para a construção de um novo conhecimento;

- o cidadão é visto como um ser integral (razão e emoção);

- a produtividade do cidadão cresce a partir do desenvolvimento de habilidades básicas.

A perspectiva ambiental consiste num modo de ver o mundo no qual se evidenciam as inter-relações e a interdependência dos diversos elementos na constituição e manutenção da vida. A principal função do trabalho com o tema Meio Ambiente é contribuir para a formação de cidadãos conscientes, aptos a decidir e atuar na realidade socioambiental de um modo comprometido com a vida, com o bem-estar de cada um e da sociedade, local e global. Para isso é necessário que, mais do que informações e conceitos, a escola se proponha a trabalhar com atitudes, com formação de valores, com ensino e aprendizagem em atividades extensivas à comunidade na qual deve estar inserida.

Educação Ambiental no Ensino Básico

O CEI tem por finalidade o pleno desenvolvimento do educando, seu preparo para o exercício da cidadania ecológica, bem como a sua preparação para o trabalho, visando:

- Capacitar jovens e adultos com conhecimentos e habilidades gerais e específicas para o exercício de atividades produtivas;

- Proporcionar a formação de profissionais aptos a exercerem atividades específicas no trabalho, com escolaridade correspondente;

- Dar condições de acesso ao conhecimento sistemático e universal a partir da realidade de vida dos alunos, favorecendo seu desenvolvimento integral;

- Estimular o desenvolvimento de atitudes crítico - reflexivas, do espírito de investigação, da criatividade e da solidariedade;

- Realizar pesquisas científicas e ensaios tecnológicos com a finalidade de fomentar o espírito inovador do educando e contribuir para o desenvolvimento tecnológico e científico do país;

- Estimular atitudes e hábitos saudáveis à vida em sociedade, em um ambiente onde todos possam: a) compreender e respeitar os direitos e 
deveres do ser humano, do cidadão, da família, dos grupos sociais e do Estado; b) acessar e dominar recursos científicos e tecnológicos que Ihes permitam situar-se, criticamente, diante da realidade, assumindo responsabilidades sociais; c) preparar-se para participar produtivamente da sociedade, através do exercício profissional responsável; e d) participar de práticas na formação para a qual se habilitou, com vistas ao futuro exercício profissional.

O CEI elabora a elevação do nível de escolaridade capacitando os jovens e adultos a desenvolver praticamente os conceitos de Cidadania e Meio Ambiente, potencializando tantos para a prática ecológica e cidadã, e colaborando com a implantação da Agenda 21 local.

Os jovens e adultos alvos dos cursos de ensino médio e fundamental do CEI constituem um grupo homogêneo do ponto de vista socioeconômico. São provenientes das classes populares, onde a necessidade de trabalhar para subsistência se coloca desde muito cedo. Do ponto de vista sociocultural, jovens e adultos se caracterizam como um grupo heterogêneo: operários da construção civil, donas de casa, empregadas domésticas, porteiros, lixeiros, balconistas, faxineiros, etc. A maioria passou em algum momento pela escola, alguns apenas meses outros cursaram alguns anos, porém o tempo de escolarização nem sempre significa mais conhecimentos e facilidade para aprendizagem. A heterogeneidade é consequência de aprendizagens e experiências em diferentes contextos sociais, com seus conceitos, crenças, valores, atitudes e procedimentos, constituindo processos diferenciados de aprendizagem, conhecimento e formas de pensamento e não diferentes potenciais para aprendizagem.

\section{Resultados}

Garantir o emprego é o grande desafio atualmente. Entretanto, em todo Brasil. Um enorme contingente de trabalhadores enfrenta uma dificuldade crescente para ingressar no mercado de trabalho ou manter-se nele. Elevar a qualidade de vida dos cidadãos, desenvolver economicamente o município, combater o desemprego, não são apenas responsabilidades dos governos. As organizações da sociedade civil, as entidades comunitárias, as empresas e o governo atuam em parceria no enfrentamento de um de nossos problemas mais urgentes. Assumindo, assim, um papel estratégico em relação ao crescimento econômico do município e, principalmente, ao bem-estar da população e do meio ambiente. Segundo relato de sua diretora, Profa ${ }^{\text {. M.Sc. }}$ Solange Maria S.N. Mattos, o trabalho desenvolvido no CEI nestes últimos cinco anos formou mais de 500 (quinhentos) cidadãos (ãs), grande parte encaminhada ao mercado de trabalho.

São grandes os desafios a enfrentar quando se procura direcionar as ações para a melhoria das condições de vida no mundo. Um deles é relativo à mudança de atitudes na interação com o patrimônio básico para a vida

revista brasileira educação ambiental 
humana: o meio ambiente. Os alunos podem ter nota 10 nas provas, mas ainda assim, jogar lixo na rua, pescar peixes - fêmeas prontas para reproduzir, atear fogo no mato indiscriminadamente, ou realizar outro tipo de ação danosa, seja por não perceberem a extensão dessas ações ou por não se sentirem responsáveis pelo mundo em que vivem. A problematização e o entendimento das consequências de alterações no ambiente permitem compreendê-las como algo produzido pela mão humana, em determinados contextos históricos, e comportam diferentes caminhos de superação. Dessa forma, o debate na escola pode incluir a dimensão política e a perspectiva da busca de soluções para situações como a sobrevivência de pescadores na época da desova dos peixes, a falta de saneamento básico adequado ou as enchentes que tantos danos trazem à população.

\section{Considerações finais}

A solução dos problemas ambientais tem sido considerada cada vez mais urgente para garantir o futuro da humanidade e depende da relação que se estabelece entre sociedade/ natureza, tanto na dimensão coletiva quanto na individual entre os gêneros de nossa espécie, quanto às nossas relações interespecíficas. A perspectiva ambiental consiste num modo de ver o mundo no qual se evidenciam as inter-relações e a interdependência dos diversos elementos na constituição e manutenção da vida. À medida que a humanidade aumenta sua capacidade de intervir na natureza para satisfação de necessidades e desejos crescentes, surgem tensões e conflitos quanto ao uso do espaço e dos recursos. A demanda global dos recursos naturais deriva de uma formação econômica cuja base é a produção e o consumo em larga escala. A lógica, associada a essa formação, que rege o processo de exploração da natureza hoje, é responsável por boa parte da destruição dos recursos naturais e é criadora de necessidades que exigem, para a sua própria manutenção, um crescimento sem fim das demandas quantitativas e qualitativas desses recursos. As relações político-econômicas que permitem a continuidade dessa formação econômica e sua expansão resultam na exploração desenfreada dos recursos naturais, especialmente pelas populações carentes de países subdesenvolvidos como o Brasil. Os rápidos avanços tecnológicos viabilizaram formas de produção de bens com consequências indesejáveis que se agravam com igual rapidez. A exploração dos recursos naturais passou a ser feita de forma demasiadamente intensa, a ponto de pôr em risco a sua renovação. Sabe-se agora da necessidade de entender mais sobre os limites da renovação de recursos tão básicos como a água, por exemplo.

Uma das principais conclusões e proposições assumidas em reuniões internacionais é a recomendação de investir numa mudança de mentalidade, conscientizando os grupos humanos da necessidade de adotar novos pontos de vista e novas posturas diante dos dilemas e das constatações feitas nessas reuniões. Por ocasião da Conferência Internacional Rio 92, cidadãos representando instituições de mais de 170 países assinaram tratados nos quais 
se reconhece o papel central da educação para a "construção de um mundo socialmente justo e ecologicamente equilibrado", o que requer "responsabilidade individual e coletiva em níveis local, nacional e planetário". E é isso o que se espera da educação ambiental no Brasil, assumida como obrigação nacional pela Constituição promulgada em 1988, e melhor compreendida agora a partir do curso ministrado na ONG. A principal função do trabalho com o tema Meio Ambiente é contribuir para a formação de cidadãos conscientes, aptos a decidir e atuar na realidade socioambiental de um modo comprometido com a vida, com o bem-estar de cada um e da sociedade, local e global. Para isso é necessário que, mais do que informações e conceitos, a escola se proponha a trabalhar com atitudes, com formação de valores, com ensino e aprendizagem de procedimentos.

É grande a dificuldade de obter uma visão mais global da realidade, uma vez que geralmente o conhecimento é apresentado para os alunos de forma fragmentada pelas disciplinas que compõem a grade curricular escolar. Entretanto, a formulação do projeto educacional do Centro de Ensino Interdisciplinar - CEI - internalizando a Educação Ambiental como disciplina por meio da discussão, decisão e encaminhamentos conjuntos, com atribuição de responsabilidades pelos corpos docentes e discentes, possibilita superar 0 fracionamento do saber. As divergências de interesses, vários exercícios profissionais e as diferentes escalas de valores, por terem que se articular na efetivação do projeto pedagógico, contribui para a construção de uma cidadania com consciência ecológica.

\section{Referências}

AZZI, S. Trabalho docente: autonomia didática e construção do saber pedagógico. In: PIMENTA, S.G. (org.). Saberes pedagógicos e atividade docente, São Paulo: Cortez Editora, 1995.

BARBIERI, J.C. Instrumentos de Política Pública Ambiental. mimeo, Rio de Janeiro, 1999.

D’ANTOLA, A. (org.). A Prática Docente na Universidade. São Paulo: Editora Pedagógica e Universitária, 1995.

FONSECA, S.M. O Valor de Existência de um Ecossistema Costeiro Tropical, Através da Disposição ao Trabalho Voluntário. Dissertação de mestrado ao PPGCA/UFF, Niterói, 2001.

IBAMA - Instituto Brasileiro do Meio Ambiente. Educação para um futuro sustentável. Edições IBAMA, Brasília, 2000.

IBGE - Fundação Instituto de Geografia e Estatística. Censo 1990 - Dados Populacionais Atualizados, Gráfica IBGE, Rio de Janeiro, 1996.

LEITE, A.L.T.A.; MEDINA-MININNI, N. (Coord.). Educação Ambiental: curso básico a distância: documentos e legislação da educação ambiental, 5 v., $2^{\underline{a}}$ edição, MMA, Brasília, 2001. 
MOREIRA, M.A. Ensino e Aprendizagem: o significado de alguns conceitos básicos segundo diferentes perspectivas teóricas. In: MOREIRA, M.A.(org.). Ensino na Universidade, sugestões para 0 professor. PADES/UFRGS/PROGRAD. Rio Grande: Editora da Universidade, 1994.

PIMENTA, S.G. Formação de professores: identidade e saberes da docência. In: PIMENTA, S.G.(org.). Saberes pedagógicos e atividade docente. São Paulo: Cortez Editora, 1994.

VIEIRA, L. Cidadania Global e Estado Nacional. Rio de Janeiro, mimeo, 1999. 